\title{
Dürfen Therapeuten in Körperöffnungen eindringen?
}

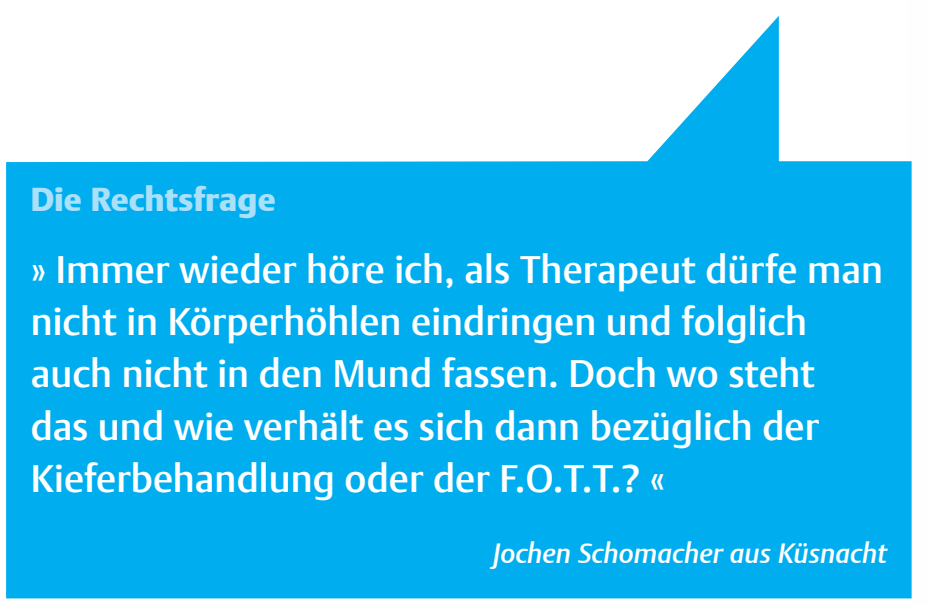

\section{Die Antwort unseres Experten}

Die Frage, ob Therapeuten auch in Körperöffnungen behandeln dürfen, wird vielfach diskutiert. Bemerkenswert ist, dass niemand begründen kann, weshalb sie nicht in Körperhöhlen wie den Mund fassen dürfen sollen.

Werden Therapeuten aufgrund einer ärztlichen Verordnung tätig, so erbringen sie ein Heilmittel nach Maßgabe des Sozialgesetzbuches V. Der Arzt bestimmt das „Ob“ und die Therapeuten das „Wie“ der Heilmittelabgabe. Sie sind laut einem Urteil des Bundesverwaltungsgerichts (Urteil vom 26.08.2009, 3 C 19/08) für die Durchführung ärztlicher Verordnungen ausgebildet und wählen die passende Methode aus.

Sind Therapeuten der Ansicht, dass für die fachgerechte Durchführung der ärztlichen Verordnung das Behandeln in einer Körperöffnung notwendig ist, so können sie dies tun. Stimmt der Patient zu, verstoßen sie gegen keinerlei Verbot. Schlägt der
Patient allerdings bestimmte Techniken aus, dürfen sie diese selbstverständlich nicht anwenden.

Konkrete (gesetzliche) Verbote von Behandlungen in Körperöffnungen existieren nicht. Berufsrechtlich sehen weder die ärztlichen noch die therapeutischen Berufsregeln irgendwelche Vetos vor. Wenn Patienten mit einer konkreten Behandlungsmethode einverstanden sind, wird kein Straftatbestand verwirklicht.

Zusammengefasst: Physiotherapeuten dürfen in Körperöffnungen behandeln, wenn sie damit eine ärztliche Verordnung erfüllen. Vor allem und gerade auch im Bereich der Kieferbehandlung dürften daher keinerlei Bedenken bestehen.

Philipp Groteloh

\section{$\Rightarrow$ Wirft auch Ihr Berufsalltag rechtliche Fragen auf? Dann schreiben Sie an Simone.Gritsch@thieme.de.}
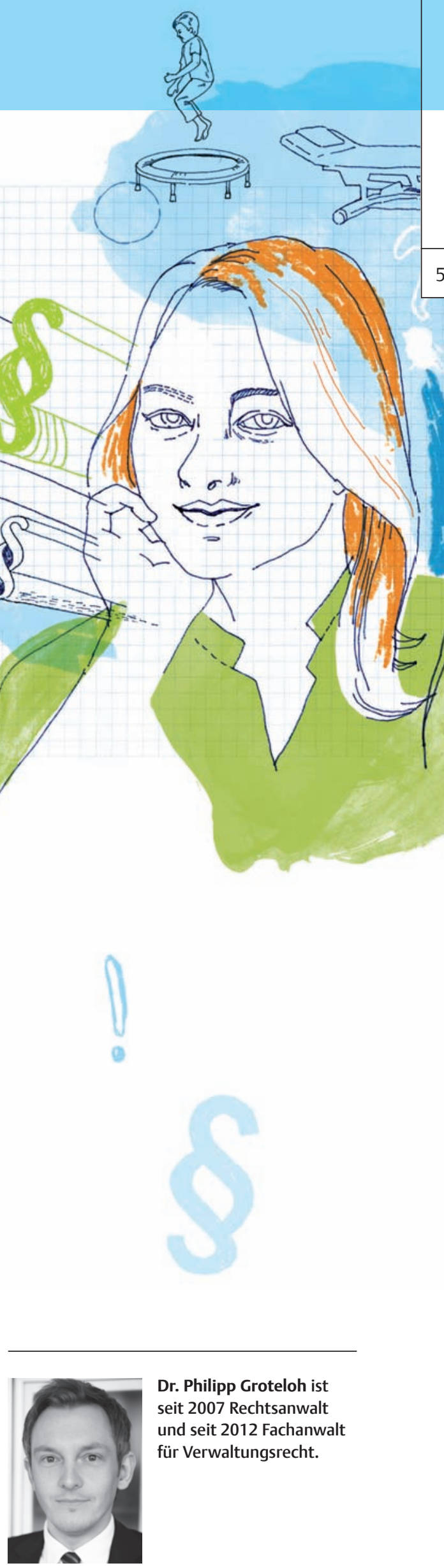

Dr. Philipp Groteloh ist seit 2007 Rechtsanwalt und seit 2012 Fachanwalt für Verwaltungsrecht. 